\title{
La alternativa fenomenólogica en el contexto de las Ciencias Sociales
}

Jorge Iván Cruz G.* Universidad de Caldas

Hoy es claro que para una reflexión y análisis crítico de las disciplinas sociales y políticas, el asunto no sólo debe enmarcarse en problemas epistemológicos sino igualmente metafísicos. Pero antes de revisar la crítica fenomenológica a la concepción naturalista de las disciplinas sociales y políticas, queremos trazar dos imágenes que confrontan al hombre en el mundo. Tales imágenes son las síntesis exploradas por Wilfrid Sellars y Edmund Husserl. Esto nos permitirá examinar la propuesta fenomenológica de Alfred Schutz sobre los fundamentos de la realidad social.

Palabras clave: imagen manifiesta, imagen científica, fenomenología trascendental, mundo de la vida, ciencias sociales.

\section{THE PHENOMENOLOGICAL ALTERNATIVE IN THE CONTEXT OF THE SOCIAL SCIENCES}

Nowadays, it is evident that in order to reflect and analyze critically political and social disciplines, epistemological and metaphysical issues must be considered. Before analyzing the phenomenological critique based on naturalist conception of social and political disciplines, there is a need to set two images which confront the man against the world. Those images are the explored synthesis by Wilfrid Sellars and Edmund Husserl. This will lead us to analyze the phenomenological proposal of Alfred Schutz about the principles of social reality.

Key words: manifest image, scientific image, transcendental phenomenology, world of life, social science.

* Docente de la Universidad de Caldas. 


\section{Imágenes manifiestas y científicas del hombre en el mundo (una lectura desde Wilfrid Sellars)}

ellars al hablar de imágenes señala que son tipos ideales o construcciones,
por ende, de ficciones. Al llamarlas imágenes no deniega la condición de
realidad y nos aclara que lo que hace es colocar entre paréntesis (para usar
la expresión de Husserl), modificar modos de tener experiencias del mundo en objetos
de reflexión y consideración filosóficas.

Pues el término de 'imagen' posee una ambigüedad muy conveniente: por una parte alude al contraste entre un objeto (un árbol, por ejemplo) y su proyección sobre un plano o la sombra que proyecte sobre un muro, y en este sentido la imagen es algo tan existente como el objeto del que sea imagen, por más que, desde luego, su estado sea de dependencia; en el otro sentido, la 'imagen' es algo imaginado, y lo imaginado puede perfectamente no existir, aunque el imaginario existe (caso en el que podemos decir de la imagen que es meramente imaginaria o irreal); sin embargo lo imaginado puede existir, como sucede cuando uno se imagina que hay alguien bailando en la habitación contigua, y realmente lo hay. ${ }^{1}$

La imagen manifiesta cómo el hombre toma conciencia de sí mismo como hombre en el mundo. Es el lugar en cuyos términos el hombre se encuentra a sí mismo, o sea, cuando se hizo un hombre. Pero Sellars afirma que el hombre es fundamentalmente un ser que piensa de sí mismo dentro de los parámetros de la imagen manifiesta; el resultado será, que si tal imagen aplicada al hombre es falsa, ello amenazará al hombre mismo, pues es el ser quien tiene esa imagen de sí mismo. Tal imagen se entenderá como una elaboración de lo que llamará la imagen 'original' del hombre en el mundo.

... pues al hablar de imagen manifiesta quiero decir que se trata de un afinado o elaboración de lo que podría llamarse la imagen 'originaria', afinado cuyo grado es tal que lo hace pertinente para la esencia intelectual contemporánea; y cabe interpretarlo bajo dos epígrafes: a) el empírico y b) el categorial. ${ }^{2}$

Por afinado empírico se entiende lo obtenido por el uso de técnicas para el escudriñamiento y establecimiento de correlaciones. Por tanto, la imagen manifiesta podría considerarse como imagen científica: " ... no solamente es disciplinada y crítica, sino que, además, emplea los aspectos del método científico que cabría agrupar bajo el epígrafe de 'inducción de correlaciones"'3

Por afinado categórico se entiende como un modo de transformación en las categorías que se usan para clasificar los objetos de la imagen manifiesta. Los objetos bases de la imagen manifiesta son las personas. Para Sellars se ha dado un afinamiento en el desenvolvimiento histórico de la imagen manifiesta a través de una etapa

1 SELLARS, Wilfrid. Ciencia, percepción y realidad. Ed. Tecnos, Madrid, 1971. Pág. 13.

2 Ibíd. Pág. 15

3 Ibíd. Pág. 15 
primitiva donde la categoría de persona lograba un alcance mayor que el actual; lo que ahora se clasifica como cosas, tiempo atrás se concibió como personas, por ejemplo:

... originariamente ser un árbol era una manera de ser una persona, lo mismo que por valernos de una cercana analogía- ser una mujer es una manera de ser una persona, o ser un triángulo es una manera de ser una figura plana... y cuando el hombre primitivo cesó de considerar como personas a lo que llamamos árboles, el cambio fue más radical que una modificación de creencias: fue un cambio de categorías ${ }^{4}$.

Ahora bien, una clara diferencia entre la imagen manifiesta y la imagen científica consiste en que en la científica se da un tipo de razonamiento: “...a saber, el que conlleva a la postulación de entidades no perceptibles, y de principios relativos a ellas, para explicar el comportamiento de las cosas perceptibles" ${ }^{\prime \prime}$. De este modo, la imagen manifiesta se limita a la observación y descripción en el mundo cotidiano (aquí se incluye a las personas y su comportamiento), a diferencia de la imagen científica.

Pero Sellars, de cierta manera acepta que la imagen científica dependa de la manifiesta, si bien en sentido metodológico se habla en primera instancia de imagen manifiesta antes que de imagen científica no se infiere de ello que por:

El hecho de que toda imagen teorética sea un edificio que reposa sobre unos cimientos proporcionados por la imagen manifiesta y que, en este sentido metodológico, presupone esta imagen lleva fácilmente a suponer que esta última es previa en un sentido sustantivo, esto es, que las categorías de la ciencia teorética dependen lógicamente de categorías referentes a su cimiento metodológico en el mundo manifiesto del sentido común alambicado, de tal suerte que la noción de un mundo que hiciera visibles sus principios teoréticos sin hacer visibles, a la vez, las categorías y principios del mundo manifiesto conllevaría un absurdo. ${ }^{6 *}$

Sellars explicita que los pensamientos no pueden definirse en su completitud en términos del comportamiento físico. Plantea que se presenta una 'intencionalidad' en los pensamientos que se consideren en cuenta, y para ello argumenta que la intencionalidad de los pensamientos se logra mediante análisis semánticos de los

4 Ibíd. Pág. 18

5 Ibíd. Pág. 15

6 Ibíd. Pág. 28

* Quienes defienden la primacía de la imagen manifiesta -por ejemplo Merleau Ponty- señalan cómo la imagen científica depende de la manifiesta para establecer la primacía de ésta. Empero, si nos acogiésemos a la posición de Sellars, tal primacía sería metodológica, y no sustantiva u ontológica. El presente obstáculo de la imagen manifiesta al desplazamiento por la imagen científica tales como: la posición de los conceptos, las sensaciones concientes, y como lo plantea si se transforma la manera cómo la imagen científica recrearía con sus propios términos las sensaciones, imágenes y sentimientos de la imagen manifiesta, la primacía de la imagen científica sólo conseguiría despegar. "Pues aun restaría la tarea de mostrar que las categorías relativas al hombre, en cuanto persona que se encuentra frente a normas -éticas, lógicas, etc.- que entran con frecuencia en conflicto con sus deseos e impulsos, pueden reconciliarse con la idea de que el hombre es lo que la ciencia dice que es" (Ibíd.. Pág. 47) 
actos de discurso abierto, además de que los pensamientos son elementos que se conciben gracias a los papeles que desempeñan. En términos generales -y esto ya se hace complejo- Sellars considera que no hay razón a priori para que no se conciba un sentido más amplio de proceso físico en el que las contrapartidas científicas de lo que se llama sensaciones se consideren como una dimensión de proceso natural o físico.

Pareciera que Sellars defendiese la primacía de la imagen científica, pues considera que los pensamientos y las sensaciones no presentan ningún obstáculo insuperable para ello. Pero se nos hace paradójico la afirmación de Sellars que el marco conceptual de las personas es el lugar en el que pensamos que los otros comparten las intenciones comunes que suministran el entorno de principios y criterios dentro del cual vivimos nuestras vidas. Esto podríamos considerarlo como un dualismo que de una parte sostiene lo que la imagen científica mantiene como real y de otro lado el marco conceptual de las personas.

Si consideramos que tales imágenes chocan con respecto a su pretensión de realidad final y las categorías necesarias para describir y explicar tal realidad, la imagen científica tendría primacía sustantiva u ontológica. Pero según Sellars como se manifestó anteriormente hay un sentido en que la imagen manifiesta sea ella misma una imagen científica, pero, en la medida que involucre un uso crítico y disciplinado de los métodos de la inducción correlacional. Las ciencias de la vida humana se comprenderían así como ciencias de la imagen manifiesta que estudian las correlaciones sistemáticas del comportamiento intencional.

De acuerdo a lo anterior, esto apoyaría el entendimiento que tendrían los científicos sociales conductistas, pues si consideramos el paso a la imagen científica se advertiría que no hay limitaciones a priori al desarrollo de tal ciencia. Dicho de otra manera, al prevalecer el interés por la descripción y explicación de lo que no sólo se circunscribe en el desarrollo de los seres humanos análogas a las ciencias de la naturaleza, del mismo modo se darían razones para creer en una convergencia de las ciencias teóricas, la imagen científica del hombre resultaría ser la de un sistema físico complejo. Pero dejemos el asunto aquí y demos paso a la fenomenología trascendental de Husserl.

\section{La fenomenología trascendental de Edmund Husserl}

La visión sinóptica del hombre en el mundo según Sellars precisa un contraste con la propuesta de Husserl. Las imágenes científicas y manifiestas del hombre son punto de partida para comprender la descripción que presenta Husserl de la ciencia positiva u objetiva y el mundo que proyecta en contraste con el mundo de la vida.

Pero hemos de advertir antes la ambigüedad presentada en Sellars al mostrar que la imagen manifiesta define uno de los polos alcanzados por la reflexión filosófica. No sólo los sistemas de la filosofía antigua y moderna tiene en sus cimientos la imagen manifiesta, sino de igual modo posturas del pensamiento contemporáneo, algunos de los cuales guardan relación con sistemas clásicos. Podría esperarse que incluya las escuelas del pensamiento europeo. 
Pues cabe entender fructíferamente todas estas filosofías, según creo, como unas exposiciones más o menos adecuadas de la imagen manifiesta del hombre -en- el mundo, exposiciones que luego se toman por una descripción plena y adecuada, en rasgos generales, de lo que el hombre y el mundo son realmente. ${ }^{7}$

Y más adelante nos señala que las filosofías que hablan del hombre en el mundo, no sólo presentan la estructura de la imagen manifiesta, sino que además adoptan tal imagen como algo real. Queda sin aclarar si la fenomenología pertenece a tal contexto. De ser así, se malinterpretaría a Husserl quien persistirá en que el mundo de la ciencia objetiva y el mundo de la vida requieren de la epojé de tales mundos en relación a su realidad.

¿Pero a qué se refiere Husserl al hablar de ciencia objetiva y mundo de la vida? La ciencia objetiva conlleva una matematización esencial del mundo, pero tal imagen tiene una historia, en donde se ubica a Galileo para aclarar lo que involucra tal concepción del mundo. Esto se afianza en el origen de la ciencia moderna bajo el ideal de una conciencia 'racional' con carácter universal que domine sin dejar fuera nada.

Y esto rige no sólo en lo relativo al espacio ideal. Mucho más alejada de los antiguos estaba la concepción de una idea análoga, pero -en cuento surgida de una abstracción formalizante- más general: la idea de una matemática formal. Sólo en los comienzos de la época moderna se inicia la verdadera conquista y descubrimiento de los infinitos horizontes matemáticos. ${ }^{8}$

\section{Husserl subraya la idealización matemática de la naturaleza por parte de Galileo}

Galileo, el descubridor de la física, esto es, de la naturaleza física... es un genio descubridor y encubridor a un tiempo. Descubre la naturaleza matemática, la idea metódica, rotura el camino de la infinitud de los descubridores y de los descubrimientos físicos. Descubre, frente a la causalidad universal del mundo intuitivo -sensible- ... lo que desde entonces es llamados sin más la ley de la causalidad, la 'forma a priori' del mundo 'verdadero' (idealizado y matematizado), la 'ley de la legaliformidad exacta', según la cual todo evento de la 'naturaleza' -de la naturaleza idealizada- viene sometido a leyes exactas. Todo esto es descubrimiento-encubrimiento, y hasta hot lo hemos asumido como la pura y simple verdad. ${ }^{9}$

Al continuar su análisis, Husserl abre la perspectiva de lo que bien se llamaría el telos de esta consideración científica. La concepción de ciencia objetiva universal ideal que involucre la matematización de la naturaleza dependerá del mundo de la vida. Husserl muestra que en la época de Galileo lo que se dio fue sustituir subrepticiamente del mundo matemático subestructurado de lo ideal en lugar del mundo real que se da gracia a la percepción que permite experimentar nuestro mundo vital.

7 Ibíd. Pág. 16.

8 HUSSERL, Edmund. La crisis de las ciencias europeas y la fenomenología trascendental. Ed. Crítica. Barcelona, 1991, Pp. 21-22

9 Ibíd. Pp. 54-55 
Es ahora de la mayor importancia considerar el desplazamiento considerado ya por Galileo, en virtud de que el mundo matemáticamente cimentado de las idealidades pasó a convertirse en el único mundo real, el mundo efectivamente dado como perceptible, el mundo de la experiencia real y posible; en una palabra: nue4stro mundo de la vida cotidiana. Este desplazamiento sustitutorio fue heredado bien por sus sucesores, los físicos de todos los siglos subsiguientes. ${ }^{10}$

Pero no hay que olvidar que para Husserl el mundo vital es pre-científico tanto por darse antes de la ciencia moderna, como por ser presupuesto de la actividad científica. Mundo vital en la que el hombre se encuentra a sí mismo como hombre. No puede ocultarse ni olvidarse que la ciencia natural tiene su arraigo en este mundo y lo presupone.

Ahora bien, Husserl muestra que los enigmas que resultan para explicitar la 'subjetividad' de la experiencia humana, y los dualismos que aparecen en la filosofía moderna, se imputan a la convicción de que el mundo de la naturaleza matemática, objetivada, se convierte en la medida de lo que es real. Husserl trazará el contraste entre imagen científica e imagen manifiesta.

No hay que olvidar que Husserl no afirma la primacía ontológica del mundo de la vida, pues ella ha de colocarse entre paréntesis para poder entender sus estructuras de significado. Se trata es de transformar lo que parece obvio y aparentemente poco problemático en un enigma y que lo convirtamos en un objeto de investigación.

Así pues, lo que se requiere es una concepción nueva de ciencia (no reducible a mera ciencia objetiva), en la cual se entiendan las estructuras generales del significado del mundo de la vida y la manera de constituirse esos significados. Pero la transformación que requiere una actitud fenomenológica es una especie de conversión religiosa.

Quizá se mostrará incluso que la actitud fenomenológica total y la epojé que le pertenece están llamadas a provocar una completa mutación personal, que cabría comparar, en principio, con una conversión religiosa, pero que, por encima de ello, esconde en sí la máxima mutación existencial que se encomienda a la humanidad en tanto que humanidad. ${ }^{11}$

De este modo, el interesado en el contexto social, participa como cualquier hombre en el mundo de la vida diaria y en la interpretación de este mundo de la vida. Como interesados en lo social se participa en formas particulares de interacción social con los otros. Se hace posible investigar la estructura y dinámica de la interacción social de las comunidades. Pero como pensadores sociales hemos de interesarnos por una representación y explicación objetiva de las estructuras y dinámicas de la vida diaria.

10 Ibíd. Pág. 50

11 Ibíd. Pág. 144 
Es por lo anterior que ha de adoptarse una posición teórica, antes que práctica propia de la acción en el mundo consuetudinario. Las hipótesis, interpretaciones, explicaciones, teorías que se proponen a cerca del mundo de la vida son objetivas en cuanto están sujetas a las normas intersubjetivas de la comunidad científica. Pero las llamadas afirmaciones intersubjetivas se refieren a los autores de la vida diaria.

Para concluir este interludio, podríamos decir que Husserl criticaría a Sellars el no realizar el giro trascendental de meditar más el proyecto de transformación de las imágenes científicas y manifiestas como formas de experiencia del mundo en objetos de la reflexión y evaluación filosóficas, en otras palabras, Sellars no advierte como el campo de la reflexión filosófica el de la subjetividad trascendental. Ello es confirmado por Merleau-Ponty cuando expresa lo que desde su punto de vista es la posición derivada de la ciencia

Todo el universo de la ciencia esta construido sobre el mundo vivido y, si queremos pensar rigurosamente la ciencia, apreciar exactamente su sentido y alcance, tendremos, primero, que despertar esta experiencia del mundo del que ésta es expresión segunda. La ciencia no tiene, no tendrá nunca el mismo sentido de ser que el mundo percibido, por la razón d que sólo es una determinación o explicación del mismo. ${ }^{12}$

Podría pensarse en cómo conciliar estas posiciones, pues no desconocemos que la ciencia puede contribuir a comprender lo que son los seres humanos, si bien ello se complementaría con una descripción de la imagen manifiesta, cabe indagar si estas imágenes: ¿son sólo dos perspectivas diferentes de la misma realidad humana, o dos aspectos diferentes de tal realidad?

Pues, como señala Sellars, si necesitáramos de ambas imágenes sin escoger entre ellas, no tomaríamos en serio la pretensión de cada imagen de constituir la explicación verdadera y completa del hombre en el mundo. ¿De qué manera hemos de evaluar las opuestas pretensiones de la imagen manifiesta y científica? ¿Con qué alternativas contamos?

Como es natural, tal y como están las cosas, esta incorporación directa de la imagen científica a nuestra gorma de vida únicamente podemos efectuarla en la imaginación; pero hacerlo, aunque sólo sea en la imaginación, es trascender el dualismo de las imágenes manifiesta y científica del hombre -en- el mundo. ${ }^{13}$

Cada imagen afirma que puede explicar a la otra. Cada una pretende ser completa y busca representar la postura fundamental desde la cual se ve la otra como algo derivado. Pero no olvidemos que un entendimiento fenomenológico del mundo de la vida es el que trata de elucidar las estructuras del mundo vital constituidas en sí mismas por la conciencia intencional. Alfred Schutz busca aclarar los conceptos

12 MERLEAU-PONTY, Maurice. Fenomenología de la percepción. Planeta-Agostini. Barcelona, 1985, Pág. 8

13 SELLARS, W. Op. Cit. Pág. 49 
básicos de una fenomenología del mundo social, en especial en su teoría del significado y la acción. En cuanto al significado lo muestra como un problema temporal de la 'conciencia inmanente del tiempo'. Es dentro de la duración individual que se constituye el significado de su experiencia a medida que viva esta experiencia. El significado es cierta forma de dirigir nuestra mirada a un elemento de nuestra propia experiencia.

Lo anterior conllevará a analizar tipos de constitución usados en la vida diaria y por los científicos sociales para captar los significados objetivos y subjetivos; además de las formas en que puedo llegar a conocer mis significados subjetivos y los de otros. Esto implicará ver en la acción la distinción entre le significado objetivo y subjetivo.

\section{Fundamentos fenomenológicos de las Ciencias Sociales según Alfred Schutz}

En el centro inicial del trabajo de Schutz encontramos interés por los fundamentos fenomenológicos de las ciencias sociales. Husserl y Schutz consideraban que en cuanto lográramos claridad de fundamentos fenomenológicos adecuados de las ciencias sociales, se abriría el horizonte para la investigación empírica que continuaría el desarrollo estas disciplinas. Dicho de otra manera la fenomenología ofrece tanto interpretación de las ciencias sociales, como de igual modo influencias sobre la investigación empírica.

Ahora bien, una fenomenología del mundo social requiere investigaciones que se entrelazan:

1. Explicación de conceptos como los del 'significado subjetivo', la 'acción', la 'intersubjetividad'.

2. Desarrollo de las distinciones y categorías para la comprensión del mundo de la vida.

3. Aplicación de lo anterior a investigaciones de fenómenos sociales específicos.

En cuanto a lo primero, el asunto del significado concebido por Schutz, es temporal en el sentido de la 'conciencia inmanente del tiempo' (punto de regencia desde Husserl en la obra de 1905 que conlleva tal título). Es sentido de la duración individual que se constituye para el significado de su experiencia a medida que se vive la experiencia. Schutz revisa cómo se constituye el en la experiencia individual de un yo solitario; ello con el propósito de introducir metodológicamente distinciones más complejas que conlleven a una teoría general de la estructura del mundo social. Para ello es menester distinguir el acto por el cual el yo constituye estructuras de significado, productos u objetivaciones, y los procesos en esta constitución, o sea, las formas en que funciona una corriente de conciencia dinámica. El significado es cierta manera de dirigir nuestra mirada a un elemento de nuestra propia experiencia.

... vivo dentro de los propios actos dotadores de significado y sólo estoy conciente de lo que se constituye objetivamente en ellos, es decir, del significado objetivo.

Sólo después de que... abandono el mundo de los objetos (Gegenstande) y dirijo 
una mirada a mi corriente interna de conciencia, sólo después de que 'pongo entre paréntesis' el mundo natural y sólo atienda a mis experiencias concientes dentro de la reducción fenomenológica, sólo después de haber hecho estas cosas cobro conciencia de este proceso de constitución. ${ }^{14}$

Aquí ya subyacen problemas para los procedimientos usados en la vida diaria y por los científicos sociales para aprehender los significados objetivos y subjetivos; además de las maneras en que se puede llegar a conocer significados en primera persona y significados de los demás. Schutz conciente de ello explorará algunos de tales problemas. Pero, es mejor presentar brevemente cómo los conceptos del comportamiento y la acción permiten distinguir el significado subjetivo del objetivo.

El comportamiento lo entiende como la experiencia de la conciencia dotadora de significado, y por ello la acción es un tipo de comportamiento. Toda acción involucra un proyecto que determina el alcance y unidad de una acción; lo que conlleva a distinguir entre la acción como proceso y el acto como producto. Un acto es el producto de una acción completa, y a su vez en esta se presenta lo que se proyecta en la anticipación del futuro.

Lo que se proyecta es el acto, que es la meta de la acción y que se genera por la acción. Supongamos que me imagino levantándome de mi silla y caminando hasta la ventana. Lo que realmente me imagino no es una serie de contracciones y relajamientos musculares, ni una serie de pasos específicos -uno, dos, tresdesde la silla hasta la ventana. No, la imagen que tengo en mente es una imagen del acto completado de llegar a la ventana. ${ }^{15}$

O sea, que es siempre el acto completado lo que imaginamos, por mucho que fragmentemos el proceso. Así, la acción es intrínsicamente significativa por la intencionalidad humana, es decir, por la conciencia.

En relación a lo segundo, al mundo de la vida diaria, el sujeto que actúa en el mundo intersubjetivo, señala Schutz: "Toda interpretación de este mundo se basa en un inventario de experiencias previas, las propias y las que comunican nuestros padres o maestros; estas experiencias en forma de 'conocimiento a disposición' funciona como un esquema de referencia."16

El sujeto perfila su mundo con un acervo de conocimiento disponible. Schutz usa este concepto en sentido amplio para hablar no solo del conocimiento sino de igual modo de las creencias, las expectativas, las reglas y los sesgos que nos permiten interpretar el mundo. este concepto se forma con las experiencias personales y con el conocimiento social que heredamos. En el transcurso de nuestra experiencia, se somete a prueba, se pule y modifica tal acervo. Dicho de otra manera, en primera instancia

\footnotetext{
14 SCHUTZ, Alfred. The phenomenology of the social World. Evanston III: Nothwestern University press, 1967. Pp. 36-37

15 Ibíd. Pág. 60

16 SCHUTZ, Alfred. Collected papers. Vol. I. La Haya: Martinus Nijhoff, 1962, Pág. 7
} 
nos encontramos en una situación biográficamente determinada. No se es sólo un se físico en un mundo espacial-temporal objetivo. Como sujetos que dan significación a las experiencias, se tiene una posición en un mundo que conlleva sentido para los sujetos. Incluso el tiempo y espacio fenomenológico en el que se vive esta constituido por la significación que se da a este mundo. De este modo al decir biográficamente determinada, es porque se tiene una historia: es la sedimentación de las experiencias previas el hombre, organizadas en su acervo disponible.

En el mundo cotidiano, el interés radica más en lo práctico que en lo teórico. “Una motivación pragmática gobierna nuestra actitud natural hacia el mundo de la vida diaria. El mundo, en este sentido, es algo que debemos modificar por nuestras acciones o que modifica nuestras acciones". ${ }^{17}$

De acuerdo con esto el acervo del conocimiento se encuentra socialmente preformado y distribuido. Este acervo en el mundo diario difiere entre la experiencia personal, grupos, clases, según el conocimiento de sentido común que se comparta. Pero por peculiar que sea nuestro acervo de conocimiento en lo que compete al contenido, estilo, claridad, diferenciación, también compartimos con otros elementos de este conocimiento de sentido común, considerando una yuxtaposición en nuestro sistema de relevancia.

En lo intersubjetivo, el mundo vital se estratifica en diversas dimensiones sociales, cada una de las cuales con sus estructuras espaciales-temporales distintivas. Mis experiencias no son idénticas a las del otro con quien interactúo de cara a cara, pero participamos en la vida conciente del otro.

Existe una sociedad de tiempo y espacio, o sea, una sincronización de corrientes de conciencia, así como una presencia corporal que permite comprender las palabras, gestos, expresiones faciales y movimientos del otro. Al captar la vida del otro es un proceso de mi vida conciente. Al interactuar, envejecemos juntos y tengo contacto inmediato con el otro, aunque este contacto se encuentre mediado por las experiencias del pasado y el acervo de conocimiento de cada uno de nosotros

Cuando te veo en la comunidad de espacio y tiempo, tengo una prueba directa de que estas orientado hacia mi, es decir, que experimentas lo que digo y hago, no sólo en un contexto objetivo de significado sino también como manifestaciones de mi vida consciente. Sé que lo mismo se aplica a ti, y que refieres tu experiencia de mí a lo que captas de mis experiencias de ti. En la comunidad de espacio y tiempo, nuestras experiencias del otro no sólo están coordinadas sino también recíprocamente determinadas por una referencia cruzada continua. Me experimento a través de ti, y te experimentas a través de mí. El reflejo recíproco de Si Mismo en la experiencia de los demás es un aspecto constitutivo de la relación-nosotros en las citaciones cara a cara. ${ }^{18}$

17 Ibíd. Pág. 209

18 Ibíd. Vol. II. Pág. 30 
Pero hay que resaltar, que si bien Schutz muestra la primacía cara a cara, no considera que ello sea suficiente para desarrollar una teoría general de la realidad social. Más bien, se propone demostrar que las diversas dimensiones del mundo social tiene sus propias estructuras. Una interacción cara a cara se encuentra constituida en primera instancia por una orientación-tú; mientras una relación social en el mundo por una orientación-ellos.

Es relevante distinguir tales dimensiones del mundo social, ya que los diversos tipos de relación e interacciones sociales que se presentan en cada una de estas dimensiones son en sí mismas diferentes. En la vida diaria, estos mundo se entre cruzan y son aspectos del mundo de la vida. Sin embargo, el fenomenólogo debe ser sensible a las estructuras diversas que se exponen en las diversas dimensiones del mundo social.

Pero Schutz también percibe otra característica que resulta de igual modo importante para la dirección y comprensión del mundo social. Es una característica donde discriminamos diferentes "provincias de significado finitas, a cada una de las cuales podemos asignar el acento de la realidad"19. El mundo en el que vivimos es el intersubjetivo de la vida diaria, en el cual no dudamos de la existencia de este mundo ni con quienes nos relacionamos. Pero de igual modo vivimos en otros mundos de provincias de significado finitas. El mundo de los sueños, imágenes, fantasías, arte, religión, ciencia, juego, locura, etc.

Hablamos de provincias de significado y no de subuniversos porque es el significado de nuestras experiencias, y no la estructura ontológica de los objetos, lo que constituye la realidad. En consecuencia, llamamos provincia de significado finita a cierto conjunto de nuestras experiencias si todas ellas muestran un estilo cognoscitivo específico y son -con respecto a este estilo- no sólo consistentes en sí mismas sino también compatibles entre sí. ${ }^{20}$

Cada provincia de significado tiene su peculiar estilo cognoscitivo y acento de realidad. Cada provincia muestra sus estructuras, relaciones espaciales y temporales, modos de relevancia, esquemas de comprensión, etc.

La reflexión sobre los sujetos y los seres sociales requiere tanto de la fenomenología constitutiva del mundo de la vida, como de la clasificación, delimitación y análisis de los otros mundos en los que se vive. Dicho de otra manera, se requiere de las diversas formas en que se interrelacionan estos mundos diferentes.

En cuanto a lo tercero la teoría de las diversas realidades de Schutz provee un horizonte interesante para el entendimiento de la teoría social y el modo ideal del teórico puro. Pues el mundo de la teoría científica es una de las diversas realidades o provincias de significado finitas delimitadas por Schutz. Pero tematizar sobre ello nos conllevaría a límites más allá del propósito del presente ensayo.

${ }^{19}$ Ibíd. Vol. I. Pág. 230

${ }^{20}$ Ibíd. Vol. I. Pág. 230 
Lo cierto es que cualesquiera que sean nuestras metas de aspiraciones prácticas como sujetos, el objetivo de la fenomenología es el de adelantar el conocimiento en sus estructuras y procesos de constitución. La tensión entre la noción de theoria y bios theoretikos es el punto de partida y el problema central de quienes buscan elaborar una teoría crítica de la sociedad.

La fenomenología es autónoma y responsable. Busca una vida de autonomía intelectual, responsabilidad y pruebas no derivadas. Además provee horizontes para el desarrollo de una comunidad moral y política.

\section{Bibliografía}

HUSSERL, Edmund. La crisis de las ciencias europeas y la fenomenología trascendental. Ed. Crítica. Barcelona, 1991

MERLEAU-PONTY, Maurice. Fenomenología de la percepción. Planeta-Agostini. Barcelona, 1985

SELLARS, Wilfrid. Ciencia, percepción y realidad. Ed. Tecnos, Madrid, 1971

SCHUTZ, Alfred. The phenomenology of the social World. Evanston III: Nothwestern University press, 1967

Recibido: Febrero 25 de 2009 - Aprobado: Agosto 17 de 2009 